\title{
La política chilena hacia Bolivia, 1900-1930: la constitución de un discurso estructural ${ }^{\star}$
}

\author{
The Chilean policy toward Bolivia, 1900-1930: \\ The establishment of a structural discourse
}

\author{
César Ross Orellana ${ }^{* *}$ \\ Instituto de Estudios Avanzados, Universidad de Santiago, Santiago de Chile
}

Recibido: 30 de diciembre 2015. Aprobado: 23 de febrero 2016.

\begin{abstract}
Resumen
Este artículo analiza la constitución del discurso internacional de Chile respecto del conflicto y del Tratado de 1904 con Bolivia, que configuró las relaciones siguientes entre ambas naciones. Se ha seleccionado el período 1900-1930, porque corresponde a las décadas durante las cuales Chile estabilizó sus relaciones con los tres países vecinos, mediante los tratados de 1902, 1904 y 1929. La hipótesis propuesta en este trabajo es que durante este período el discurso y la política chilena se consolidaron. Por una parte, este discurso se elaboró bajo un enfoque racional y jurídico, basado en un proceso más profundo y asociado a la constitución de la identidad chilena, cuyos componentes catalizaron con la Guerra del Pacífico. Por otra, ambas, identidad y discurso, se volvieron verdades pétreas, cuya vigencia se ha mantenido hasta el presente. La elaboración de este trabajo se basa en la Memoria anual del Ministerio de Relaciones Exteriores de Chile, la principal fuente que nos informa sobre este discurso y de la política a que éste dio lugar.
\end{abstract}

Palabras claves: Bolivia/Chile, Tratado de 1904, relaciones internacionales.

Este artículo es parte de la investigación financiada por CONICYT Anillos SOC1109 "Relaciones transfronterizas entre Bolivia y Chile: paradiplomacia y prácticas sociales 1904-2004”, del Instituto de Estudios Internacionales de la Universidad Arturo Prat y el Doctorado en Estudios Americanos de la Universidad de Santiago de Chile.

** Profesor de Historia y Geografía, Universidad Metropolitana de Ciencias de la Educación (UMCE), magíster en Historia, Universidad de Santiago de Chile (USACH), doctor en Estudios Americanos, Mención Relaciones Internacionales, USACH. Profesor Titular, USACH; investigador, Instituto de Estudios Avanzados (IDEAUSACH). Director del Doctorado en Estudios Americanos, USACH. Correo electrónico: cesar.ross@usach.cl 


\begin{abstract}
This article analyzes the constitution of international discourse about the conflict of Chile and Bolivia Treaty of 1904, which set the following relations between the two countries. Is selected the period 1900-1930, because it corresponds to the decades during which Chile stabilized its relations with the three neighboring countries through treaties of 1902, 1904 and 1929. The hypothesis proposed in this paper is that during this period the speech and Chilean politics were consolidated. On the one hand, this speech was prepared under a rational and legal approach, which is based on a deeper process and associated with the establishment of the Chilean identity, whose components catalyzed with the Pacific War. Furthermore, both identity and address, Gritty truths became, whose validity has remained to the present. The preparation of this work is based on the annual report of the Ministry of Foreign Affairs of Chile, the main source informs us about this speech and politics to which it gave rise.
\end{abstract}

Keywords: Bolivia/Chile, Treaty of 1904, international relations.

\title{
Introducción
}

Este trabajo se inscribe dentro de un enfoque de política exterior y dentro de ella (Ross, 2012), examina el discurso sobre la política exterior de Chile respecto de Bolivia en el período histórico aludido en el título. En este contexto, las referencias a las relaciones bilaterales, al presente y a las teorías de relaciones internacionales, son de carácter auxiliar y no central.

En el campo internacional, las decisiones se elaboran en función de las percepciones que se tienen de la realidad. Tal y como lo señalan los estudios contenidos en el magnífico trabajo editado por Richard K. Herrmann (2013), acerca del lugar de la percepción y de la imagen en la teoría de las relaciones internacionales, se decide en función de lo que se percibe que es la realidad. Ésta representa los datos objetivos de la realidad (siempre discutibles); no solo refleja el espectro de los intereses en juego, sino que, y muchas veces maniqueamente, adquiere las funciones que cada jugador requiera para alimentar su propia estrategia. 
Como ha sostenido Jack S. Levy (2003), respecto de la política exterior, y como ha argumentado el mismo Herrmann en relación con la teoría de la imagen y la interacción estratégica en las relaciones internacionales, la percepción no sólo opera como un "inconsciente", sino que como un constructo basado en datos objetivos, en selección de argumentos que parecen creíbles, sistematización de repertorios de amenazas y, como en el caso que nos convoca, en el enorme peso de la historia.

Muchos acontecimientos han sido objeto de este tipo de lectura, pero especialmente aquellos que tienen historicidad, por lo cual han pasado a formar parte de la memoria de las naciones, cuyo devenir se ha conectado reiteradas veces con las relecturas que cada generación ha hecho de los eventos que modificaron el curso de la historia nacional, al menos en la percepción de los observadores nacionales.

Aún más relevantes han sido aquellos fenómenos que han involucrado a terceros países y de cuya acción se han derivado cambios significativos. En el espectro total de acontecimientos que generan memoria y percepciones con efectos residuales, la guerra ocupa el primer lugar, no sólo por el trauma que implica la pérdida de vidas humanas, sino también por los demás efectos colaterales (como pérdida de territorios, pagos de indemnizaciones, humillaciones simbólicas, etc.), que no desaparecen cuando el luto -ya sea por la muerte de los difuntos o por el olvido- ha quedado en el pasado.

Además, porque las guerras generan un cúmulo gigantesco de verdades a medias que, puestas en libros de Historia, adquieren el estatus de verdad, sobre todo cuando el tiempo borra los rastros específicos de los hechos, cuando los protagonistas ya han fallecido y cuando las generaciones siguientes se nutren únicamente de aquellas versiones para acceder al pasado. Como propuso Esquilo de Eleusis (525-456 a.C.), en una línea repetida hasta el extremo: "La verdad es la primera víctima de la guerra". Podría agregarse que, también en la historia y en las historias derivadas de las guerras, la verdad también adquiere una utilidad instrumental, sea ésta revestida de un manto de racionalidad, sea de emoción. Las relaciones de Chile y Bolivia, así como los discursos que se elaboraron a partir ellas, no han estado exentos de estos dilemas.

La historia, en cuanto pasado, es siempre escrutada desde el presente y, en demasiadas ocasiones, con las inquietudes y preguntas del presente. Así ocurrió sobre todo durante el llamado positivismo del siglo XIX, en cuya pretensión principal estaba la idea de que la reconstrucción pormenorizada de los hechos era suficiente para conocer el pasado, sin perjuicio de que los rastros del mismo eran, por decir lo menos, un fragmento insuficiente de esa totalidad, un residuo a veces intencionado de esa historia. 
La Historia, en cuanto reconstrucción del pasado, no sólo adoleció de estas consideraciones teórico-metodológicas durante el siglo XIX y una buena parte del siglo XX, sino que además estuvo sujeta, como en la Grecia o Roma clásicas, a los relatos hechos por sus protagonistas que, de primera $-\mathrm{y}$ subjetiva- mano, contaban sus propias experiencias. La mayoría de estos relatos, surgidos de las vivencias traumáticas de la guerra, eran presentados como epopeyas, vale decir, historias dramáticas, protagonizadas por héroes (nacionales) y antihéroes (antagonistas), que contaban hazañas que contribuyeron a crear los mitos fundacionales de las ideas de nación y de la pertenencia a ella.

La Guerra del Pacífico fue un evento que marcó a fuego a los tres países involucrados (Bolivia, Chile y Perú) y se constituyó en el acontecimiento histórico clave para catalizar los procesos de construcción de estas tres naciones.

Estas representaciones fueron adquiriendo una importancia mayor para países cuyas identidades estaban en formación. Siguiendo la tesis que Mario Góngora (2010) y William Sater (1973) escribieron para el caso de Chile, podría afirmarse que el país modeló buena parte de su autoconcepto en el proceso de construcción del Estado. Así, en Chile primero fue el Estado y después la nación. Ésta fue resultado de un proceso histórico que también estuvo jalonado por las experiencias múltiples en que las guerras (Góngora, 2010), y en especial la Guerra del Pacífico (Sater), se constituyeron en un factor crítico en la formación de la nación en términos de delinear una identidad patriótica, heroica, guerrera, disciplinada al orden, al respeto a la ley, a la defensa del territorio y a una serie de otros atributos que antes habían tenido un carácter más bien temporal y superficial. La experiencia de la guerra cristaliza los ideales nacionales en la figura de Arturo Prat y eleva no sólo a este héroe al estatus de "santo secular" (Sater, 1973), sino que a toda esa generación a un nivel moral superior. Del mismo modo, los relatos que ellos hacen de esa experiencia traumática adquieren una posición de verdad incuestionable, cuyo fundamento reside en el valor social atribuido al sacrificio impuesto por la guerra. El país reforzó su identidad de Estado basado en instituciones sólidas y en el imperio de la ley. En esta trayectoria, el punto más destacado fue que en medio de esta guerra en Chile hubo campañas electorales y elección presidencial, ${ }^{1}$ sin que el conflicto alterara el itinerario establecido por la Constitución Política del Estado, como un claro reflejo del compromiso de los ciudadanos y de la profundidad institucional del país. ${ }^{2}$

El 18 de septiembre de 1881 dejó el cargo Aníbal Pinto Garmendia y asumió la Presidencia de la República Domingo Santa María González, quien permaneció en el cargo hasta el 29 de agosto de 1886.

2 En el Chile de entonces, como casi todas las repúblicas de su época, la ciudadanía era ejercida por una porción muy pequeña de hombres educados y con dinero, los únicos que podían votar. En consecuencia, se trataba del país que ese grupo había forjado para sí. 
El resultado ha sido una trayectoria nacional marcada por la estabilidad política, la que ha reforzado el autoconcepto de un país confiable (predecible). Hasta el 2015, Chile ha tenido 197 años de independencia y 38 gobiernos, lo que equivale a un promedio de 5,2 años por gobierno. ${ }^{3}$

En términos generales, la Guerra del Pacífico ha operado el mismo efecto sobre Bolivia, pero en sentido contrario. De esta misma guerra emergen sus máximos héroes, ${ }^{4}$ de ella también surgen casi los únicos ideales capaces de unir a un país plurinacional y profundamente fragmentado por identidades territoriales (collas y cambas), culturales (multinacionalismo), lingüísticas (al menos con aymara, quechua y español) y por una exclusión social extrema, que hasta el día de hoy son un rasgo distintivo del país. Ante la imposibilidad histórica de "construir" una identidad nacional homogénea, las élites bolivianas han invocado la Guerra del Pacífico una y otra vez para aglutinar a la población frente a conflictos internos.

El resultado, como lo acreditan los datos expuestos y el sólido estudio de Alberto Alesina, ha sido una trayectoria nacional marcada por la inestabilidad política y el subdesarrollo (Alesina, Ozler, Roubini y Swagel, 1996). Hasta el año 2015, Bolivia ha tenido 189 años de independencia y 100 gobiernos, lo que implica un promedio de 1,9 años por gobierno.

De este modo, y sin perjuicio de los fundamentos más o menos verdaderos de las ideas que han sustentado estas identidades, ellas operan socialmente como verdades pétreas $\mathrm{y}$, en tal sentido, nutren las percepciones de quienes, a uno y otro lado de la frontera, construyen versiones acerca de la realidad propia, de la del otro y de la relación con el otro. Es clave considerar que las trayectorias nacionales fueron ajustando los relatos, de modo de convertirlos en versiones consistentes, al menos en apariencia, y respecto de las cuales no cabe reflexión crítica o alternativa.

En Bolivia y Chile, los grupos nacionalistas, frecuentemente vinculados a la derecha conservadora y a las instituciones armadas, han exacerbado estas visiones, las que han convertido en repositorio de sentido para todas sus acciones.

En una visión esquemática, planteo que en ambos países también, y durante el siglo XX, los partidos políticos de izquierda, frecuentemente identificados con las causas del tercer mundo y con el paradigma neoidealista de la integración como una forma de convivencia,

3 Incluyendo el gobierno de Augusto Pinochet y contando por separado los tres gobierno dobles del período conservador del siglo XIX.

4 Como Ladislao Cabrera y Eduardo Abaroa. 
levantaron un fuerte discurso para terminar con las brechas (divisiones) entre los pueblos de América Latina, identificando como la verdadera amenaza el imperialismo de Estados Unidos y visualizando el Sur y el tercer mundo como el verdadero objetivo de sus causas, donde la superación del subdesarrollo, la cooperación y la integración eran las piezas clave.

En las décadas de 1960 y 1970 del siglo XX, la polarización ideológica entre izquierda y derecha se identificó con estas visiones contrapuestas entre nacionalistas e integracionistas, coincidiendo históricamente con el enfrentamiento que hubo entre las dictaduras militares y las insurgencias revolucionarias surgidas, en su mayoría, desde los partidos políticos de izquierda. ${ }^{5}$ Así, el repertorio internacional del pensamiento de derecha, estuvo centrado en el nacionalismo y, por extensión, en la visión del vecino como un enemigo. Por su parte, la izquierda se identificó más con un internacionalismo, de raigambre revolucionaria, signado por la búsqueda de la integración y de una cierta unidad transnacional de los pueblos.

De este modo, la brecha epistemológica entre unos y otros se volvió política y se incrementó aún más. Esta distancia, que hasta la década de 1980 era ideológica y local (en cada país), pues coincidía con la identificación política de clases y grupos, volvió a crecer en las décadas siguientes y se volvió internacional debido al giro a la derecha de Chile (reformas ortodoxas: gobierno de Pinochet, de la Concertación y siguientes) y al giro a la izquierda de Bolivia (reformas heterodoxas: gobiernos de Evo Morales).

De esta forma, en las últimas décadas, en Chile el discurso de los vencedores asumió la forma de un relato racional, frío, insensible y propio de las élites tradicionales que en las últimas décadas habían mantenido una connivencia cómplice con la dictadura cívicomilitar encabezada por Augusto Pinochet, además de identificarse con el neoliberalismo económico y mostrarse insensible frente a las desigualdades que de él se han derivado.

Por su parte, en Bolivia, el discurso de los vencidos asumió la forma de un relato emocional o también llamado "emotivista" (Sánchez, 1919), sensible ante la pérdida de la llamada "cualidad marítima", conectado con el sentimiento popular (no elitista) sobre el mar; asoció esta pérdida al subdesarrollo (Montenegro, 1943), y en las últimas décadas

\footnotetext{
Sin duda que hubo grupos armados contrarios a las dictaduras, como ERP y Montoneros, que tuvieron su origen en partidos políticos de izquierda, así como hubo grupos paramilitares que se originaron en partidos de derecha o en el seno mismo de las Fuerzas Armadas con visiones más conectadas con el pensamiento fascista (sobre todo hasta el término de la Segunda Guerra Mundial) y, durante la Guerra Fría, con la doctrina de la seguridad nacional (Washington), que con alguna otra ideología.
} 
se identificó con el sector social castigado por las dictaduras y las reformas neoliberales que, de la mano de su actual líder (Evo Morales), se han levantado reclamando justicia social y la reparación por la pérdida de los recursos naturales que les pertenecen ancestralmente, vale decir, antes de la construcción del Estado nacional y antes de la conquista y colonización españolas.

Estos relatos de país y estos discursos de política exterior, sin embargo, no sólo han alcanzado esta forma por la trayectoria de siglo XX, que muy brevemente he sintetizado hasta aquí, sino que por una identidad aún más antigua, que se configuró durante los siglos coloniales, se consolidó en el siglo XIX y que puede verse en acción durante los primeros 30 años del siglo XX.

Se ha seleccionado el período aludido porque durante ese lapso Chile debió negociar tratados de límites con sus tres vecinos: 1902 con Argentina, 1904 con Bolivia y 1929 con Perú.

Se ha optado por trabajar con Chile porque suele ser señalado como el país que posee la llave de la solución y que conserva una conducta rígida respecto de opciones que se distancien del Tratado de 1904. En este sentido, el trabajo está estimulado por el interés de indagar en la profundidad de dicha rigidez.

En las próximas páginas se presenta un análisis del discurso chileno oficial respecto del conflicto con Bolivia y su solución. El objeto de este trabajo, y cuyo resultado expongo aquí, ha sido desentrañar las claves de este discurso, a fin de comprender más profunda y detalladamente no sólo los pormenores de su argumentación, sino también las concepciones más profundas que subyacen en él y que podrían explicar la primacía del enfoque racionalista (no únicamente jurídico) de las relaciones exteriores que imperó en el caso estudiado y que, quizás, podría inferirse para toda la política exterior chilena de esa época.

Mi hipótesis sostiene que el discurso chileno respecto del conflicto con Bolivia, y su solución, estuvo basado en el dominio de la lógica liberal (Fariña y Huerta, 1991) dominante en la élite nacional que gobernó el país durante el período posterior a la Guerra del Pacífico y hasta 1930. Ésta no sólo logró acuñar una visión de este asunto, sino que logró traspasar a las generaciones siguientes dicha mirada, con independencia de los contenidos que nutrieran la relación con Bolivia o con cualquier otro actor externo. Racionalismo (Devés, 2000; Zea, 1976), utilitarismo (Neira, 2004) y positivismo (Zea, 1980; Subercaseaux, 1980) que de este modo quedó fundido en la forma de decodificar 
la realidad externa y que hoy categorizamos con conceptos como realismo, neorrealismo, neoliberalismo y pragmatismo.

La metodología de este trabajo ha sido relevar el discurso de política exterior de Chile hacia Bolivia, en los términos señalados, a partir de las Memorias anuales del Ministerio de Relaciones Exteriores de Chile, documento oficial presentado anualmente por el ministro de turno como resultado de su gestión. Este documento, por oficial y por ser escrito por la élite dirigente del período, refleja cabalmente la mirada de los gobiernos y las intelectualidades hegemónicas. Adicionalmente, estos documentos representan muy bien la lógica que subyace a la forma de construir sus razonamientos.

Este artículo está organizado en dos partes. La primera, justifica la idea de examinar el discurso. La segunda, está referida a la constitución y características del discurso chileno, 1900-1930. El trabajo termina con una breve conclusión.

\section{Discurso público como discurso político internacional}

\section{Qué entendemos por discurso}

El análisis de discurso se constituyó en una disciplina independiente en las décadas de 1960 y 1970, gracias a los aportes de muchos intelectuales que sobrepasaron con creces el ámbito específico de la lingüística y que abarcan un espectro muy amplio de las ciencias sociales y humanas. Hasta aquí ha sido una herramienta útil que ha permitido develar visiones de la realidad, ocultas detrás de una textualidad superficial que usualmente busca presentar una versión más amable de la realidad, pero que, puesta en contexto, permite observar aquello que no se quiere decir o aquello que no se sabe bien que se piensa y que trasunta en el discurso.

A diferencia del uso que le han dado los lingüístas, expertos en comunicación social y cientistas políticos, que han ocupado el análisis de discurso de manera estricta, los historiadores lo hemos usado de un modo más heterodoxo para procesar piezas documentales que podrían permitir resolver algunas tensiones observadas entre las versiones oficiales sobre la realidad y lo que ha parecido ser la verdadera visión de 
ella. Esta anomalía, paradoja o contradicción entre lo que se supone que es y lo que aparentemente es, ha desafiado los métodos tradicionales de análisis hermenéutico y ha abierto el espacio para este método.

Habida cuenta de su utilidad y considerando el tiempo transcurrido desde su entrada en escena como disciplina autónoma, el análisis de discurso ha recibido la atención de muchos académicos, cuyos aportes hoy es posible condensar en una serie de publicaciones sumarias que dan cuenta de sus avances con regularidad (Gee y Handford, 2012; Tannen, Hamilton y Schiffrin, 2015).

Así, por ejemplo, en dos destacadas publicaciones, una de Routledge durante el año 2012 (Gee y Handford, 2012) y otra de Wiley Blackwell en 2015 (Tannen, Hamilton y Schiffrin, 2015), pueden encontrarse una serie de autores destacados cubriendo aspectos sustantivos de la cuestión que nos interesa. En el libro de 2012 pueden mencionarse los trabajos de los profesores Jürgen Jaspers sobre la sociolingüística internacional y el análisis de discurso; Ruth Wodak acerca de los discursos políticos en acción; Teun van Dijk en torno al discurso y el conocimiento; y Adrian Blackledge acerca del discurso y el poder. En el texto de 2015 destacan los trabajos de Laurel J. Brinton sobre el análisis del discurso histórico, Teun van Dijk respecto del análisis crítico del discurso y John Wilson en relación al discurso político.

Sin perjuicio de la cantidad y variedad de autores, Teun van Dijk resulta omnipresente y muy funcional a los intereses de este trabajo, por ello nos centraremos en él, sobre todo en los libros que nos parecen centralmente importantes.

Siguiendo la argumentación de Teun A. van Dijk (1999),

Los discursos académicos son inherentemente partes de la estructura social, por la que están influidos, y que se producen en la interacción social. En lugar de denegar o de ignorar las relaciones entre el trabajo académico y la sociedad, los analistas críticos proponen que tales relaciones sean estudiadas y tomadas en consideración, y que las prácticas académicas se basen en dichas observaciones. La elaboración de teoría, la descripción y la explicación, también en el análisis del discurso, están «situadas» sociopolíticamente, tanto si nos gusta como si no. La reflexión sobre su papel en la sociedad y en la vida política se convierte así en constituyente esencial de la empresa analítica del discurso. (1999, p. 24). 
Ésas son cuestiones fundamentales concernientes al papel del discurso en el orden social. En lugar de ofrecer reflexiones filosóficas globales sobre tal papel, el Análisis Crítico del Discurso (ACD) proporciona detallados y sistemáticos análisis de las estructuras y estrategias de texto y habla, así como de sus relaciones con los contextos sociales y políticos (van Dijk, 1999; Coulthard y Caldas-Coulthard, 1996; Fowler, Hodge y True, 1979; Wodak y Chilton, 2005).

\section{Discurso público y discurso internacional}

Un discurso político e internacional no tiene únicamente las características generales que van Dijk identifica en un discurso tipo, ${ }^{6}$ sino que tiene el potencial de desplazar al ámbito externo, tanto los conflictos como las oportunidades de integración, de modo de alimentar y constituir un verdadero universo simbólico que tiene la característica de operar como una matriz de todos los significados, como un decodificador maestro de todos los contenidos que se refieren a una realidad dada; en este caso, referida a la forma como vemos lo internacional y a cómo proyectamos los vínculos de un país hacia otros actores más allá de las fronteras.

De este modo, no solo el discurso político de las autoridades, a modo de alocución, tiene el potencial de operar de la manera aludida más arriba, sino que asimismo lo tiene el texto elaborado en un ámbito más reducido y destinado a un público más especializado. Cuando este tipo de discurso (contenido en fuentes oficiales o de ese carácter) se transforma en una fuente, referencia y orientador de una posición y política internacional, podemos inferir que de él es posible aprender y aprehender aquellos aspectos más profundos y permanentes, que nos ayudan a identificar patrones que muchas veces están en la base de la conducta internacional de los países.

6 Características: 1. El ACD trata de problemas sociales; 2. Las relaciones de poder son discursivas; 3 . El discurso constituye la sociedad y la cultura; 4 . El discurso hace un trabajo ideológico; 5 . El discurso es histórico; 6. El enlace entre el texto y la sociedad es mediato; 7. El análisis del discurso es interpretativo y explicativo; 8 . El discurso es una forma de acción social. 


\section{El discurso del vencedor}

En este contexto, el discurso del vencedor podría concebirse de dos modos: primero, como un conjunto de significados articulados respecto del pasado y derivados de una realidad histórica objetivable, aunque en su extremo pudiera referirse a un universo simbólico basado en una historiografía fabricada a la medida; y, segundo, como un dispositivo de convencimiento, fuera por la vía de la "afección", para consumo interno (dirigido a los connacionales), o por la de la "opresión simbólica" (Bourdieu, 2012) para exportación (destinada a los vencidos).

El vencedor apela a los suyos para legitimar sus acciones pasadas y para relegitimar la convicción general de que ellas fueron necesarias. Ésta es la función de la historiografía y de sus reproductores: los profesores en los centros educacionales, los editores periodísticos y los políticos deseosos de subir en las encuestas de opinión pública.

El vencedor también se dirige a los vencidos para reafirmar cuatro cuestiones fundamentales: las causas que le obligaron a entrar en el conflicto; la naturaleza forzosa que adquirió el proceso resultante (o las consecuencias); la inevitabilidad del desenlace final del conflicto; y, pese a todo lo anterior, la generosidad del vencedor frente al vencido, todo lo cual le lleva a concluir que el resultado final no solo es justo, sino que debe ser preservado; la inestabilidad de la contraparte como limitante de las relaciones subsiguientes.

\section{La constitución del discurso chileno, 1900-1930}

\section{El mito fundacional, 1904}

Un mito fundacional suele explicar el origen de un rito, de un hecho y de un contexto en el que algo se inicia. El mito tiene de verdad y de falsedad, según el lado en que se ubiquen los observadores. Para la primera acepción aceptada por la Real Academia Española RAE, se trataría de una narración maravillosa situada fuera del tiempo histórico y protagonizada por personajes de carácter divino o heroico. Esto le da al mito un estatus 
de fantasía y no de realidad; vale decir, lo convierte en un relato sin valor histórico o, más específicamente, sin historicidad.

Sin embargo, y con independencia de su desapego a los hechos, el mito, en tanto versión aceptada por la mayoría, opera como verdad incuestionable en la formación de opinión pública. Aún más, en la medida en que el mito se plasma en los textos escolares, él se transforma en verdadero, como cualquier hecho que sea demostrable empíricamente (Cavallo y Cruz, 2010).

Para las versiones bolivianas de la Guerra del Pacífico y sus consecuencias, ${ }^{7}$ el Tratado de 1904 (Concha y Garay, 2013) es la expresión máxima del mito de una Bolivia victimizada por el imperialismo chileno que, en pos de su ambición económica, invadió a su vecino bajo la "excusa" del incumplimiento de los acuerdos arancelarios ${ }^{8}$ para arrebatarle sus recursos naturales, razón por la cual se derivaron las subsecuentes consecuencias en el subdesarrollo e inestabilidad política crónica en las que cayó el país. La guerra pasó de ser una tragedia coyuntural a un drama estructural.

Para las versiones chilenas, por el contrario, el mito heroico, acuñado por relatos como el de Alonso de Ercilla, ${ }^{9}$ Nicolás Palacios ${ }^{10}$ y Francisco A. Encina, ${ }^{11}$ la Guerra no es sino la síntesis de la superioridad chilena, cuyo fundamento tenía que ver con explicaciones racialistas, que estarían en la base del éxito chileno, graficadas en logros, como la breve crisis pos-Independencia y su posterior desarrollo económico que, como acreditó Benjamín Vicuña Mackenna en 1882, habían producido un país rico antes de 1879

Entre otros, autores como: Daniel Sánchez Bustamante, Miguel Mercado Moreira, Carlos Alberto Salinas Baldivieso, y Carlos Montenegro Quiroga y Jorge Escobari Cusicanqui. Estos autores, con enfoques nacionalistas (idealistas o realistas), abordaron la cuestión de las relaciones con Chile y la mediterraneidad de Bolivia.

8 Establecidos en el artículo $4^{\circ}$ del Tratado de 1874, que estipulaba el compromiso que contrajo Bolivia, por el término de 25 años, de que "las personas, industrias y capitales chilenos situados en la zona cedida por Chile al norte del paralelo 24, no quedarían sujetos a más contribuciones, de cualquier clase que sean, que a las que al presente existen". Este acuerdo fue roto por Bolivia en 1878 al intentar subir los impuestos a los chilenos.

9 Militar y escritor español (1533-1594), autor de La Araucana (1569), obra épica de exaltación militar, donde alaba la raza indígena chilena.

10 Médico chileno (1858-1911) que, junto a su hermano Senén, luchó en la Guerra del Pacífico, participando en las batallas de Tacna, Chorrillos y Miraflores, hasta ingresar con el Ejército chileno a Lima. Influenciado por el evolucionismo de Charles Darwin y Herbert Spencer, postulaba que el pueblo chileno constituía una raza superior, producto del mestizaje de los conquistadores de raza goda y los araucanos. En 1904 publicó su libro Raza chilena, donde desarrolla esta tesis.

11 Historiador nacionalista (1874-1965), cuya cumbre fue su Historia de Chile (20 volúmenes), donde su exposición del pasado de Chile denota la influencia de la obra de Nicolás Palacios, aunque con un racionalismo aparentemente más sutil. Esta obra alcanzó gran difusión hasta el presente.

\section{Si Somos Americanos. Revista de Estudios Transfronterizos}


(Villalobos, 1987). ${ }^{12}$ Así como la guerra elevó estos valores a un nivel superior (mito), la madurez del sistema político nacional capitalizó las conquistas de territorios y recursos, activando un nuevo ciclo económico positivo, que se extendió hasta 1930, y consolidando un crecimiento económico que, si bien no derivó en desarrollo, en los términos de CEPAL, logró transformar positivamente la economía y la sociedad chilenas. Del mismo modo, este mito cierra su razonamiento con lo que podríamos llamar la tensión fundamental entre bolivianos y peruanos a raíz de la guerra, debido a las acusaciones cruzadas por la pérdida territorial, que les llevaron a una relación de amor/odio de la que daba cuenta la diplomacia chilena ya en 1901.

Los hechos nos convencieron de que, si era posible armonizar los intereses de Chile con los del Perú o con los de Bolivia, aisladamente, era imposible calmar las desaveniencias y rivalidades latentes y no disimuladas entre los antiguos aliados de la Guerra del Pacífico. Aunque parezca inverosímil, es la triste verdad que la diplomacia peruana y la boliviana, ofuscada [sic] por un sentimiento irreflexivo, aunque explicable, parecieron desde ese momento empeñadas más que en evitar a su propio país una situación difícil, en crear dificultades al antiguo amigo a quien acusaban recíprocamente de infidencia y deslealtad. (Ministerio de Relaciones Exteriores [Minrel], 1901, p. 23).

Esta tensión boliviano-peruana, a veces larvada u otras veces expuesta, es uno de los factores subsumidos en el discurso chileno (S. González, 2006). Cuando se afirma que Chile ha cumplido con todo lo establecido en el Tratado de 1904, implícitamente se afirma que cualquier eventual conversación para solucionar el tema de Bolivia implica la aceptación de un tercero: Perú. En 1920, a raíz de una nota dirigida por el entonces embajador boliviano en París, general Ismael Montes, a la cancillería francesa respecto de las pretensiones bolivianas de salir al mar mediante una fórmula que buscaba que Chile y Perú le cedieran Arica y Tacna, el ministro de Relaciones Exteriores de Perú, Melitón Porras, le respondió en duros términos y quizás, por ello mismo, con la sinceridad que produce no sólo una causa muy sentida, sino que la rabia de experimentar que se está tratando de imponer un deseo por sobre un derecho. Bolivia pretendía volver al mar a través de un territorio que una vez había pertenecido a Perú y que éste había perdido en una guerra a la que había sido convocado por Bolivia: "Perú está dispuesto a no ceder sus derechos sobre las provincias irredentas a favor de Bolivia o de cualquier otro país ni escuchar siquiera proposición alguna al respecto" (Figueroa, 1992, p. 20).

12 Lista publicada originalmente en El Mercurio, el 26 de abril de 1882, y reproducida por Villalobos (1987, pp. 5359). 
Esta posición, que refleja muy bien la postura de Perú hasta el presente, remitía a Bolivia y a Chile a la bilateralidad de su relación, y al acuerdo que ambos habían suscrito de común acuerdo y en un ambiente de cordialidad, como queda de manifiesto en este trabajo.

En consecuencia, y por ser un acuerdo bilateral, para ambos países el Tratado de 1904 se convirtió en la materialización de estos convencimientos. Bolivia como víctima, desplazando hacia Chile las causas de casi todos sus males, y Chile como héroe, fundando en su propia identidad las razones de su éxito. El Tratado es la ratificación de la razón del vencedor y del error del vencido. El mito quedó constituido y los discursos de ambos países lo consolidaron a partir de entonces, pese a que estas visiones se venían configurando desde antes.

En 1901, la Memoria del Ministerio de Relaciones Exteriores de Chile explicitaba una posición que se volvería estructural:

Por buenas o malas razones, que no es del caso analizarlas aquí, Bolivia había sido la causa de la guerra de 1879, a la cual fuimos arrastrados después de negarse reiteradas veces ese país a someter las diferencias ocurridas al juicio de un árbitro, como Chile lo propuso: vencidos en la guerra Bolivia y su aliado, después de habernos obligado a hacer inmensos sacrificios de sangre y de dinero, no solo no pagó aquella ni un centavo de indemnización, sino que confiscó los bienes de los ciudadanos chilenos que estuvieron a su alcance, a quienes posteriormente ha habido que resarcir siquiera en los intereses de sus capitales perdidos, con parte de las entradas de un puerto chileno. (Minrel, 1901, pp. 19-20).

Y agregaba el documento, crudamente:

Pues bien, en cambio a la insignificante faja de tierra que Bolivia cedería a Chile para no interrumpir la continuidad de su territorio y como única indemnización de guerra, nuestro representante en La Paz tenía instrucciones de ofrecerle: $1^{\circ} \mathrm{El}$ pago de diversos créditos contra el Gobierno de Bolivia reconocidos por él y que ascendían a varios millones de pesos; $2^{\circ}$ Una suma de dinero suficiente para construir una línea férrea que uniera el interior de Bolivia con algún puerto de la costa; y $3^{\circ}$ Extensión absoluta de derechos para la internación y exportación de productos bolivianos por el puerto que sirviera de arranque al citado ferrocarril y dejar a Bolivia en libertad de gravar los productos chilenos en la forma que tuviere a bien, renunciando así a los privilegios que le garantiza en Pacto de Tregua.

194 Si Somos Americanos. Revista de Estudios Transfronterizos 
Contra lo que era de esperarse, estas bases que consultaban concesiones tan amplias como generosas, no fueron aceptadas por el Gobierno de Bolivia. (Minrel, 1901, p. 20).

Como todo mito fundacional, la posición chilena está cimentada sobre una "epopeya" (la Guerra del Pacífico), cuyos héroes y antihéroes adquirieron un estatus arquetípico. Ello, al punto de que el propio Arturo Prat fue elevado, en las palabras de William Sater (1973), a la condición de Santo.

A juzgar por esta denominación y por la persistencia de este tipo de discurso en las fuentes chilenas, todo parece indicar que entre la trágica muerte de Prat (1879) y la negociación del Tratado (1904), se configuró una visión paradigmática de la posición chilena. En este lapso de 25 años, a mi juicio, se habría estructurado el "mito fundacional" que sostiene este discurso y la posición chilena frente a Bolivia.

\section{Los contenidos del discurso}

En septiembre de 1900 y a consecuencia de una heterogénea visión de la propia diplomacia chilena, el Ministerio de Relaciones Exteriores de Chile emitió una circular resumiendo lo que sería la doctrina que la política exterior chilena defendería hasta el presente como su discurso oficial (Minrel, 1901).

Al Perú que Chile haría uso de la amplitud del derecho que le otorgaba el Pacto de Ancón, y que entendía reservase para sí el dominio de Tacna y Arica, en caso de serle favorable el plebiscito; y a Bolivia, que estaba dispuesto a compensarle generosamente el litoral ocupado e título de indemnización, en cambio de acordar cuanto antes las bases de una paz definitiva, pero eliminando de esas bases sus exigencias sobre Tacna y Arica, por cuanto ese territorio no pertenecía a Chile y por cuanto no podía éste subordinar su tranquilidad a una condición eventual y de plazo indefinido.

[Estas instrucciones] expresan el propósito inquebrantable de esta Cancillería, el propósito que mantendrá con indeclinable firmeza hasta llegar al desenlace final del litigio, propósito, en fin, que es el resultado de una penosa experiencia de diecisiete años y de convencimiento profundo de que desviarse de él es desviarse del único camino que puede conducir a un arreglo común. (Minrel, 1901, pp. 25-26). 


\section{Las causas que lo obligaron a entrar al conflicto}

Éste es uno de los tópicos centrales del discurso chileno y respecto del cual se presenta abundante evidencia. Los relatos historiográficos rastreables hasta el presente han completado esta afirmación que ya en los años de iniciarse la guerra estaba en la percepción general de los chilenos.

La Memoria de 1901 planteaba que:

El límite anterior a la Guerra, desde los primeros años de su existencia, fue siempre el paralelo $23^{\circ}$ por lo menos. La autoridad de los más antiguos y autorizados historiadores, las disposiciones legislativas de los soberanos españoles y los actos jurisdiccionales de las autoridades chilenas, durante la época del coloniaje y durante nuestra vida de nación independiente, son contestes y uniformes en este punto jamás controvertido antes de 1842. (Minrel, 1901, pp. 25-26)

Una vez que inversionistas chilenos descubrieron riquezas minerales en ese territorio, Bolivia comenzó a reclamarlo como propio. Así, y después de un detenido debate entre las cancillerías de ambos Estados, Chile cedió sus derechos hasta el paralelo $24^{\circ}$, a cambio de concesiones políticas y comerciales, otorgadas por Bolivia a Chile, cuestión que quedó plasmada en el tratado bilateral de 1866.

Con todo, es relevante anotar que las Constituciones Políticas de ambos países, ${ }^{13}$ como era de uso y costumbre sobre todo en la primera mitad del siglo XIX, no identificaron los límites más que mediante expresiones ambiguas y asociadas a denominaciones tan vagas como "el despoblado de Atacama", "se fijarán sus límites, de acuerdo con los Estados limítrofes" o "una ley especial arreglará la división territorial". En consecuencia, no se identificaron las fronteras con exactitud, lo cual indujo a imprecisiones de todo tipo, que los países fueron abordando e intentando resolver en la medida en que avanzaron las exploraciones a terreno y en que se contó con la tecnología para realizar tal propósito. En tal sentido, acuerdos específicos, como el de 1866, fueron la fórmula habitual para zanjar esas diferencias y, a partir de ellos, estos países, como los demás en la misma época, resolvieron sus fronteras en términos más técnicos, lo que no daba lugar a interpretaciones ulteriores. Sin embargo, para la interpretación chilena, la conducta boliviana fue diferente.

Bolivia: 1825, 1826, 1831, 1834, 1835, 1839, 1843, 1851, 1861, 1868, 1871 y 1878. Chile: Constituciones Políticas de $1811,1812,1814,1818,1822,1823,1828$ y de 1833 (vigente hasta 1925). 
En 1911, cuando el desenlace jurídico del conflicto estaba zanjado, el enfoque chileno sobre las causas de la guerra no sólo era el mismo, sino que parecía estar consolidado.

Conviene dejar constancia de que los poseedores de dichos derechos privados, a quienes el Gobierno de Bolivia les negó su validez y aun los muy pocos a quienes los subordinaba a condiciones no realizadas, guardaron silencio y nada hicieron en su defensa, resignándose con la anulación establecida en dicho decreto, seguido poco después de la ocupación bélica del litoral sin que los interesados hicieran valer ningún derecho privado, de nacionales o extranjeros, invocando como título el haber sido legalmente adquiridos.

Dicha situación constituye el Statu-quo ante bellum, que razonablemente ha debido imponer la actitud observada por Chile. (Minrel, 1911, p. 48).

Como puede apreciarse, el enfoque jurídico chileno enfatizó el argumento central que dio lugar a la guerra, la ruptura de un acuerdo que vulneraba un conjunto de derechos de un grupo importante de chilenos que no sólo hacía negocios en el entonces litoral boliviano de Antofagasta, sino que vivía y hacía mucho por el desarrollo de la zona. Se suele perder de vista este aspecto, que muy bien han destacado los trabajos de José A. González, en los que queda muy bien acreditada la casi nula presencia del Estado boliviano y de sus ciudadanos en la costa, así como parece muy evidente la presencia de la comunidad chilena, que es la que realmente puso en valor los recursos de esta zona.

Según José A. González (2010) y basado en el Censo hecho por el Municipio de Antofagasta, hacia 1879 , más del $85 \%$ de la población de Antofagasta era chilena. ${ }^{14}$

La población chilena, sobre el $85 \%$ del total en Antofagasta hacia 1879, había sido clave en la configuración cultural del territorio. Primeramente, desde la fundación de la Municipalidad en 1872, decidiendo el rumbo de constante desarrollo de la urbe con la necesaria regulación de sus disímiles actividades y también con las presiones conjuntas de comerciantes y mineros de la zona respecto a la opción por el puerto de Antofagasta en vez de Mejillones como salida de exportación de la minería de plata de Caracoles desde 1870. (J. González, 2010, p. 347).

14 Hacia 1875, en base al censo practicado por la Municipalidad de Antofagasta, la ciudad contaba con una población de 5.384 habitantes, de los cuales 4.530 eran chilenos, o sea, un 84,13\% del total. (En Delgado, 1883, p. 363 cirado por J. González2010, p. 347). 
La situación de esta ciudad era equivalente a otras del mismo litoral boliviano (Tocopilla, Cobija, Mejillones), lo que permite relativizar de manera sustantiva la cuestión de la soberanía, no sólo porque no estuvo suficientemente delimitada en las Constituciones Políticas, sino por no haber un ejercicio concreto de ella en la ocupación y desarrollo del territorio. En el litoral, el Estado boliviano estuvo muy ausente. Podría plantearse que su soberanía fue más normativa que empírica. Ésta no es una consideración fútil, si tomamos en cuenta que para esta misma época, e incluso en períodos posteriores a ella, los Estados que litigaban territorios argumentaban la presencia y/o ausencia de una de las partes en litigio en el lugar, como una de las bases de legitimidad para reclamarlo. Fue, por ejemplo, el caso de las disputas de Argentina y Chile por la Patagonia. ${ }^{15}$

De este modo, la concepción de soberanía no apelaba únicamente a un derecho normativo sobre el territorio, sino que a uno empírico, que a ojos de los tribunales internacionales parecía predominar, pese a que el debate sobre el asunto ha sido intenso y no definitivo. ${ }^{16}$

\section{Incumplimiento reiterado de los tratados suscritos por Bolivia}

Otro aspecto instalado en el discurso chileno respecto de Bolivia es su incumplimiento de los tratados suscritos con Chile, instalándose la imagen de un país "poco serio", cuya palabra no es confiable, tanto en relación con los compromisos pasados, como de aquellos que eventualmente pudieren acordarse en el futuro.

La Memoria citada de 1901 planteaba que, pese al irrestricto cumplimiento chileno del Tratado de 1866, Bolivia no correspondió del mismo modo, incumpliendo todas sus estipulaciones. Esto se repitió respecto del "análogo pacto" de 1874, pero de manera aún más "hiriente" (sic):

Chile satisfizo religiosamente todos los compromisos que se imponía, sin que pudiese obtener de Bolivia el cumplimiento de uno solo de los que le afectaban (...) Chile no tuvo término ni límite sino que el día en que Bolivia, después de invalidar permanentemente en el hecho los tratados, declaró explícita y oficialmente que no estaba dispuesta a cumplirlos en lo sucesivo. Y viniendo a la provocación de la palabra la provocación de hecho, infirió a nuestro país agravios extremos, que parecían

Ver, entre otros: Eyzaguirre (1983), Barros (1971).

16 Baste recordar los aportes de Hans Kelsen, Karl Schmitt y Hermann Heller. 
absolutamente incomprensibles hasta el día en que vino a explicarlos el descubrimiento de un Tratado secreto de alianza ofensiva firmada contra Chile por el Perú y Bolivia. (Minrel, 1901, p. 28).

Esta parte del discurso se fundamentó con una base empírica suficiente como para que ella adquiriera un estatus de verdad para los chilenos, especialmente cuando por acción de la política y diplomacia argentina ${ }^{17}$ y brasileña ${ }^{18}$, respectivamente, se descubrió aquel tratado secreto entre Bolivia y Perú, a consecuencia de la propuesta boliviana. Este pacto privaba a ambos países, pero sobre todo a Bolivia, de toda legitimidad en su relación con Chile, por cuanto era la acreditación de lo que hoy podríamos llamar mala fe. La asunción, por parte de Chile, de la existencia de un pacto bélico en su contra, hizo que la confianza en los vecinos del Norte cayera a cero, con todas las consecuencias previsibles que de ello podían derivarse.

\section{La inevitabilidad del desenlace final del conflicto}

Calificada metafóricamente como el camino de la justicia y del buen derecho, la posición chilena justificó su reacción calificándola como un derecho de reivindicación. Para la posición de esta cancillería, Chile recuperó lo que era suyo, lo que no había dejado nunca de pertenecerle por no haber cumplido el concesionario (Bolivia) las condiciones indispensables de la cesión. Al decir de la Memoria de 1901:

Chile recobró su territorio norte hasta el paralelo 23; no alegó para ello la razón del vencedor, sino la propiedad del dueño legítimo y tradicional; Bolivia no fue desalojada de una pulgada de suelo, sino que invalidó por acto propio el contrato de cesión celebrado con Chile, reponiendo así las cosas al estado en que se hallaban antes de 1866, y pasando con ello al dominio de su primitivo dueño la propiedad cedida en virtud de un contrato anulado por el cesionario. (Minrel, 1901, p. 28).

En los términos de la Memoria, o sea, del discurso aludido, el fin de la guerra a la que fuimos provocados, y que tan incalculables sacrificios impuso a Chile, el Perú transfirió

Información recibida por el congresista chileno Guillermo Blest Gana en 1873.

18 A comienzos de 1874, el canciller brasileño João Mauricio Wanderley, Barón de Cotegipe, informó personalmente al Presidente Federico Errázuriz de este tratado secreto. 
a Chile, a título de indemnización bélica, su departamento de Tarapacá. Quedó entonces, entre el antiguo límite norte de Chile (paralelo $23^{\circ}$ ) y la desembocadura del río Loa, una

angosta y poco valiosa zona de litoral boliviano, que se interponía como solución de continuidad en el territorio de la República [Chile] (...) aquella estrecha faja de suelo que, como queda dicho, no tenía más valor material que el que le dieran el trabajo y el capital chilenos. (Minrel, 1901, p. 29).

Este territorio era lo que daba la cualidad marítima a Bolivia y su salida al Pacífico, ambas condiciones que se perdieron a causa de la derrota en la guerra.

\section{La generosidad del vencedor frente al vencido: Tratado de 1904}

Para la visión chilena, el Tratado de 1904 demuestra la generosidad del vencedor frente al vencido, lo cual le llevó a concluir que el resultado final no sólo era justo, sino que debía ser preservado.

Para la percepción diplomática chilena posterior a la guerra, la convicción fue que las autoridades bolivianas se habían reconciliado con Chile. Antes y después de la suscripción del Tratado de 1904, las manifestaciones de esta conducta quedaba ratificada con múltiples gestos que la diplomacia chilena acreditada en La Paz transmitía a Santiago, demostrando que este nuevo estado de cosas era una señal clara de que ambos países asumían que en 1904 había habido justicia para ambos Estados, habida cuenta del origen y de los costos de la guerra.

Las memorias anuales del Ministerio de Relaciones Exteriores de Chile así lo acreditaron a contar de 1900:

Es grato declarar que nuestro Ministerio ha tenido la suerte de encontrar allí [Bolivia] una benévola acogida y dado el espíritu de cordialidad que reina entre las dos cancillerías, me halaga la esperanza de que ha de llegar en época no muy lejana a producirse el acuerdo tan deseado por los gobiernos y que envuelve tanta trascendencia para las futuras relaciones de amistad y de comercio en que debe basarse el recíproco desarrollo de ambas naciones. (Minrel, 1900, p. 16). 
En 1902 era posible advertir que, más cerca de un acuerdo, el tenor del ambiente era similar. Nada que pudiese avalar que se estaba en medio de un ambiente tensionado por una coacción chilena, fundada en la superioridad militar o alguna otra hipótesis de amenaza de ese tipo.

Si bien es sensible para el infraescrito [el ministro ${ }^{19}$ ] no haberse arribado aun al arreglo amistoso y equitativo de las cuestiones pendientes con el Perú, es satisfactorio dejar testimonio de la buena inteligencia que desde hace algún tiempo se viene acentuando con la República de Bolivia. (Minrel, 1902, p. 155).

Sobre estos particulares se llegó a una inteligencia casi completa, quedando la negociación suficientemente avanzada para darle término una vez que se constituyera la representación diplomática de uno i otro país, por medio de nombramiento de Ministros Plenipotenciarios. (Minrel, 1902, p. 156).

Una expresión aún mayor puede verse en la visita del embajador chileno a Sucre, en mayo de 1909, con motivo de las festividades conmemorativas del primer movimiento por la Independencia, las que nuevamente acreditan el buen momento de las relaciones, con posterioridad a la suscripción del Tratado de 1904.

Anheloso el Gobierno de la República de tomar participación el júbilo patriótico del pueblo boliviano, se impartieron instrucciones a nuestro Ministro en La Paz, señor don Manuel J. Vega, a fin de que se trasladase oportunamente a Sucre y asistiese a las festividades con que se celebró e en dicha ciudad el 25 de mayo de 1909, fecha que marcó el transcurso de un siglo desde el primer movimiento realizado en la República hermana para conquistar su independencia.

Durante su visita a Sucre, nuestro representante y el Adicto Militar, coronel Hurtado Wilson, que lo acompañaba, recibieron múltiples y delicadas atenciones de parte de la sociedad y autoridades bolivianas. (Minrel, 1909, p. 17).

Lo mismo puede decirse de los vínculos de amistad que se fueron constituyendo entre los cuerpos diplomáticos a los que correspondió la tarea de llevar adelante los consensos entre los Estados, a fin de concretar el Tratado de 1904. Con motivo del fallecimiento

9 Por tratarse de una memoria, el documento representa la versión oficial del gobierno. En 1902, Chile tuvo dos ministros de Relaciones Exteriores: Horacio Pinto Agüero y José Francisco Vergara Donoso. 
del embajador de Bolivia en Santiago, se produjo una reacción que demuestra no sólo formalidad diplomática, sino un verdadero sentido de amistad.

Dolorosa impresión causó en nuestro país el prematuro fallecimiento, acaecido en La Paz, del Enviado Extraordinario y Ministro Plenipotenciario de Bolivia en Santiago, Excmo. señor Sabino Pinilla.

El gobierno exteriorizó su pesar en una nota de condolencia, y el Ministro de Chile en La Paz, en virtud de las instrucciones de este Departamento, asistió a los funerales del Señor Pinilla, y pronunció en ellos sentidas palabras para demostrar que el duelo de Bolivia afectaba vivamente a nuestro Gobierno, que tantas ocasiones había tenido de conocer y apreciar las distinguidas prendas personales del extinto y su inteligente y fructífera labor en pro del acercamiento entre ambos pueblos. (Minrel, 1909, p. 16).

En aquél mismo año 1909 se informaba respecto de la construcción del ferrocarril de Arica a La Paz, una de las pocas cuestiones que tardó en ser implementada, dado el tamaño de la inversión y los plazos que implicaba su ejecución.

Con este mismo propósito, y en cumplimiento de las obligaciones contraídas por la Republica, se ha dado vigoroso impulso a la construcción del Ferrocarril de Arica a La Paz, línea que, una vez entregada al tráfico, contribuirá poderosamente a la realización del plan de mutua aproximación que han tenido en vista ambos Gobiernos. (Minrel, 1909, p. 17).

En síntesis, en consideración de los costos asociados a la implementación de los acuerdos suscritos por Chile con Bolivia y en orden a la legitimidad que ambas partes le dieron al Tratado de 1904, se creó un ambiente de cordialidad, que hace muy difícil creer el hecho de que las negociaciones hubieran estado mediadas por la amenaza. Los registros de la época más bien dan cuenta de un contexto de entendimiento, en el que ambas partes tomaron beneficios del acuerdo, especialmente Bolivia, dadas las circunstancias en que se originó la guerra, su escasa participación y su reducida cuenta en el balance de las pérdidas humanas.

Como es bien sabido, en un conflicto que duró más de cuatro años, Bolivia luchó únicamente en tres batallas durante el primer año de la guerra. Las hostilidades se llevaron a efecto en las batallas de Calama (o Topáter), Canchas Blancas y en la Tambillo. Posteriormente, las fuerzas bolivianas se unieron a las peruanas en una fuerza aliada. 
La estadística oficial sostiene que Chile tuvo alrededor de 8.900 muertos, en un país que según el Censo de 1875, tenía una población de 2.075.971. Para el caso de Bolivia, fueron alrededor de 4.000 y para el caso de Perú, alrededor de 15.000 muertos (Ahumada, 1891).

En síntesis, se registró un número altísimo de bajas, entre las cuales Bolivia perdió el menor contingente. Por su parte, Perú perdió el mayor número de vidas que cualquier otro beligerante y muy probablemente ése es un dato significativo para explicar su tensión con Bolivia y su negativa a que la demanda de acceso soberano al mar de Bolivia se resuelva con territorios antiguamente peruanos, perdidos con un costo tan alto.

\section{Inestabilidad de la contraparte como limitante de las relaciones}

Un aspecto sustantivo para abrir la conversación bilateral a una nueva arquitectura de acuerdo, ha sido la desconfianza chilena en la estabilidad política de Bolivia, fundada en la debilidad estructural de sus gobiernos, los que, o bien, no logran permanecer en el poder durante el período establecido en sus propias Constituciones Políticas, o bien, intentan permanecer en el poder más allá de esos plazos, con argumentos o recursos ilegítimos.

La Memoria de 1901, así lo acreditaba:

Circunstancias del todo ajenas a la voluntad de esta cancillería y perfectamente conocidas por el Soberano Congreso, han hecho fracasar una vez más los proyectos de arreglo definitivo empeñosamente buscados por este Gobierno, y de sus esfuerzos en este sentido no ha quedado otro resultado benéfico [más] que el de haber hecho públicos, una vez más, nuestros sinceros deseos de llegar cuanto antes a soluciones definitivas y mutuamente satisfactorias, con países con los cuales hay motivos especiales para vivir en franca y sincera amistad. (Minrel, 1901, p. 15).

En efecto, como se planteó en la Introducción a este trabajo, la inestabilidad boliviana ha sido crónica ${ }^{20} \mathrm{y}$, a diferencia de lo sostenido en la clásica argumentación esgrimida por La Paz, la guerra y la pérdida de la cualidad marítima no agravó dicha condición.

20 Desde su fundación y hasta 1909, cuyo gobierno fue electo en 1904, hubo 40 gobiernos, con una duración promedio en el poder de 2 años, una vida muy similar a la de toda la vida de Bolivia, cuya cifra es de 1,9 años promedio por gobierno. 
La evidencia demuestra que antes de la Guerra del Pacífico la rotación de gobiernos fue mucho mayor que después del conflicto. Desde la fundación de Bolivia (1825) y hasta 1879, año de término del gobierno de Hilarión Daza, la duración promedio de los gobiernos bolivianos fue de 1,6 años, habiendo existido sólo uno que duró el tiempo establecido por la Constitución ${ }^{21}$ y habiendo existido varios que duraron unos pocos meses. Por su parte, y desde el inicio de la guerra y hasta 1909, fin del gobierno de Ismael Montes, la duración promedio de estos gobiernos fue de 3,3 años. En consecuencia, no podría atribuirse a la guerra y a la pérdida del acceso soberano al mar, la inestabilidad política boliviana y los problemas económicos y sociales que este país ha padecido a lo largo de su historia.

La percepción chilena de esta realidad contundente ha fortalecido el discurso nacional en este punto y ha consolidado la idea de que no hay verdadera relación entre estos factores (acceso al mar y desarrollo), asunto que autores bolivianos como Carlos Montenegro, influyente ideólogo del MNR, procuraron asociar en una causalidad a todas vistas espuria (Montenegro, 1943). Esta conexión apareció por primera vez en el debate boliviano en 1943, en el libro del autor mencionado (Nacionalismo y coloniaje), obra publicada a 64 años de iniciada la Guerra del Pacífico, en 1879, y a 39 años de suscrito el Tratado de 1904. Según Gustavo Rodríguez Ostria, se trató de una construcción elaborada por la intelectualidad boliviana y, como escribió este mismo autor, "fundando una de las pocas interpelaciones comunes que une a bolivianos y bolivianas" (Rodríguez Ostria, 2014). No se trató, pues, de una convicción histórica fundada en una creencia y/o en una dimensión central de la identidad boliviana, sino que en una elaboración post factum que buscaba darle sentido a una unidad que de modo natural no se había dado.

\section{La persistencia del discurso}

En junio de 2014, a 110 años de la suscripción del Tratado de 1904, el Ministerio de Relaciones Exteriores de Chile publicó el documento titulado "Chile y la aspiración marítima boliviana: mito y realidad” (Minrel, 2014). En él se puede apreciar que el discurso establecido en el marco del Tratado aludido sigue totalmente vigente.

En síntesis, y como ya se ha planteado en diversas fuentes, el documento aludido cuenta con tres componentes que resumen la clave de la posición chilena: primero, que Bolivia

$21 \quad$ Manuel Isidoro Belzú Humerez, que gobernó entre 1850 y 1855. 
tiene acceso al mar; segundo, que Chile y Bolivia poseen límites claros y definitivos, fundados en un tratado plenamente vigente (1904); y tercero, que lo que está en juego es el desarrollo normal de las relaciones internacionales y el respeto por los límites establecidos.

Siguiendo el razonamiento planteado en el debate realizado durante el establecimiento del Tratado mencionado, el Tratado de Paz y Amistad de 1904, Chile reconoció en favor de Bolivia y a perpetuidad "el más amplio y libre derecho de tránsito comercial por su territorio y puertos del Pacífico" (Concha y Garay, 2013).

Del mismo modo, el texto se refiere a la autonomía aduanera, preferencias tarifarias y facilidades de almacenamiento, exenciones tributarias y libre desplazamiento por las rutas de conexión con los puertos que Chile entregó a Bolivia, beneficios derivados del Tratado de 1904, sino que de diversos instrumentos suscritos bilateralmente y que Bolivia desconoce en su reciente demanda.

En el marco de la Sociedad de las Naciones (1919-1923), Bolivia hizo una presentación cuya aspiración era someter el Tratado de 1904 a revisión. La posición de Chile fue la misma que había planteado desde el inicio de la Guerra del Pacífico y durante los años posteriores: la no imposición del Tratado dada la dilación de su suscripción tras el fin de la guerra, el cumplimiento total que Chile había dado a los compromisos suscritos en 1904, destacando el libre acceso al mar que se le había dado a Bolivia, cuyos estándares superan incluso lo establecido por la Convemar (Naciones Unidas, 1994).

Del mismo modo, se argumentó respecto de la incompetencia de la Sociedad de las Naciones para conocer este asunto, así como en la amenaza que se imponía al orden internacional la eventual revisión del Tratado de 1904, porque ello supondría abrir la puerta para revisar todos los acuerdos por territorio, lo que era particularmente grave en el período pos-Primera Guerra Mundial, dada la situación de Europa. ${ }^{22}$

Estos razonamientos siguieron del mismo modo hasta el cierre histórico de este análisis (1930) y, como hemos apreciado, han permanecido relativamente así hasta el presente.

Abundante argumentación planteada por Chile en Ministerio de Relaciones Exteriores de Chile, Memoria anual, 1919-1923, Santiago. 


\section{Conclusión}

Si bien en el cuerpo de este artículo hay conclusiones específicas, en este trabajo se ha llegado a cuatro conclusiones generales fundamentales.

En primer lugar, y en atención a todo lo anterior, es posible afirmar que el discurso chileno, desarrollado en el período 1900-1930, se elaboró desde una argumentación jurídica, racional y lógica, que adquirió carácter estructural. Esta afirmación, que podría ser "trivial", en consideración del período en que aquél fue formulado y en atención a que la mayoría de los diplomáticos y políticos de la época eran abogados, es relevante porque estructuró un tipo de razonamiento que en la época tenía carácter racional y, precisamente por no ser emocional o emotivista, parecía tener estatus científico y, en dicha medida, verdadero. Esta lectura del pasado, del discurso y de la política chilena fue aceptada por la población chilena, no solamente debido a nacionalismo, sino por resultar razonable y creíble.

En segundo término, se observa que el discurso chileno surgió y adquirió su forma total y definitiva muy tempranamente. Los contenidos del discurso y sus afirmaciones principales provienen, principalmente, de las convicciones emanadas de la guerra y de la fórmula diseñada en el Tratado de 1904, que se constituyó en la pieza clave que resultó tanto del conflicto como del esquema en que ambos países vieron su lugar en el continente y respecto de las relaciones que tendrían entre sí. La aceptación bilateral de este Tratado, suscrito a 21 años de concluido el conflicto y no habiendo fuerzas movilizadas en la zona de controversia, le dio plena legitimidad al acuerdo, cuestión que fue impugnada por Bolivia en 1919, como parte de un diagnóstico que hicieron durante la pos-Primera Guerra Mundial, producto de cálculos apresurados respecto del cambio de paradigma internacional (wilsoniano), lo que podría haber favorecido a su causa. Una estimación muy apresurada, a juzgar por la suerte que corrió Alemania, fruto de aquel conflicto. En tercer lugar, se concluye que los contenidos del discurso se han mantenido relativamente inalterados, principalmente en cinco cuestiones: las causas que le obligaron entrar al conflicto; la naturaleza forzosa que adquirió el proceso resultante; la inevitabilidad del desenlace final del conflicto; pese a todo lo anterior, la generosidad del vencedor frente al vencido, todo lo cual le lleva a concluir que el resultado final no sólo fue justo, sino que debe ser preservado; y la inestabilidad de la contraparte como limitante de las relaciones subsiguientes. Todos estos argumentos han sido abordados por la historiografía chilena e internacional -no boliviana- referida a la guerra, y coinciden y acreditan la convicción nacional respecto de estos puntos. El discurso persiste hasta el presente. 
Por último, se plantea que la mantención del discurso acredita que la política de Chile ha sido consistente y que ha hecho honor al Tratado de 1904 por más de un siglo. En la base de esta continuidad está la genuina convicción que adquirió en Chile este discurso, tanto porque fue difundido sistemáticamente por variados medios, como porque el razonamiento con que fue elaborada la narración que explicaba los hechos, guardaba una profunda relación con la identidad chilena, que cristalizó con la guerra que dio lugar a este Tratado. Así, identidad y discurso quedaron férreamente unidos, dándose sentido mutuamente y nutriendo la política exterior derivada de esa interacción. De este modo, además, el discurso alcanzó una legitimidad muy profunda y transversal entre los chilenos.

\section{Referencias}

Ahumada, P. (1891). Guerra del Pacífico. Recopilación completa de todos los documentos oficiales, correspondencias y demás publicaciones referentes a la guerra. Tomos I-VIII. Valparaíso, Chile: Imprenta El Progreso.

Alesina, A., Ozler, S., Roubini, N. y Swagel, P. (1996). Political instability and economic growth. Journal of Economic Growth 1 (1), 189-211.

Barros, M. (1971). Historia diplomática de Chile, 1541-1938. Santiago, Chile: Andrés Bello.

Blackledge, Adrian (2012). Discourse and power. En Gee, J. P. y Handford, M. The routledge handbook of discourse analysis (pp. 616-627). Nueva York, Estados Unidos: Routledge.

Bourdieu, P. (2012). Sobre la televisión. Barcelona, España: Anagrama.

Brinton, Laurel J. (2015). Historical Discourse Analisys. En Tannen, D., Hamilton, H. E. y Schiffrin, D. (eds.). The Handbook of Discourse Analysis (pp. 222-243). Malden, MA: Wiley Blackwell.

Cavallo, A. y Cruz, N. (2010). Las guerras de la guerra. Editorial Aconcagua.

Concha, J. M. y Garay, C. (2013). El Tratado de 1904: Negociaciones e intereses involucrados. La Paz, Bolivia: Plural. 
Coulthard, M. y Caldas-Coulthard, C. (1996). Texts and practices: Readings in critical discourse analysis. Londres, Inglaterra: Taylor \& Francis.

Devés, E. (2000). El pensamiento latinoamericano en el siglo XX. Entre la modernización y la identidad. Tomo I: Del Ariel de Rodó a la CEPAL (1900-1950). Santiago-Buenos Aires: Biblos-DIBAM.

Eyzaguirre, J. (1983). Breve historia de las fronteras de Chile. Santiago, Chile: Editorial Universitaria.

Fairclough, N. y Wodak, R. (1997). Critical Discourse Analysis. En T. van Dijk, Discourse as Social Interaction (pp. 258-284). Londres, Inglaterra: Sage.

Fariña, C. y Huerta, M. A. (1991). El liberalismo chileno en sus orígenes: una aproximación a sus tesis. Revista de Estudios Públicos 43, 427-452.

Figueroa, U. (1992). La demanda marítima boliviana en los foros internacionales. Santiago, Chile: Editorial Andrés Bello.

Fowler, R., Hodge, B. D. y True, T. (1979). Language and control. Londres, Inglaterra: Routledge and Keegan Paul.

Gee, J. P. y Handford, M. (2012). The routledge handbook of discourse analysis. Nueva York, Estados Unidos: Routledge.

González, J. (2010). La Provincia de Antofagasta. Creación y consolidación de un territorio nuevo en el Estado chileno: 1888-1933. Revista de Indias LXX (249), 345-380.

González, S. (2006). Arica y la Triple Frontera. Integración y conflicto entre Bolivia, Perú y Chile. Iquique, Chile: Ediciones Aríbalo.

Góngora, M. (2010). Ensayo histórico sobre la noción de Estado en Chile en los siglos XIX y XX. Santiago, Chile: Universitaria.

Herrmann, R. K. (2013). Perception and image theory in international relations. The Oxford Handbook of Political Psycology. Oxford: Oxford University Press. 
Jaspers, Jürgen (2012). International sociolinguistics and discourse analisys. En Gee, J. P. y Handford, M. The routledge handbook of discourse analysis (pp. 135-146). Nueva York, Estados Unidos: Routledge.

Levy, J. S. (2003). Political Psychology and Foreign Policy. En D. O. Sears, L. Huddy y R. Jervis (eds.), Oxford Handbook of Political Psychology (pp. 253-284). Oxford: Oxford University Press.

Ministerio de Relaciones Exteriores de Chile. (1900). Memoria Anual del Ministerio de Relaciones Exteriores de Chile. Santiago, Chile.

-_-—. (1901). Memoria Anual del Ministerio de Relaciones Exteriores de Chile. Santiago: Chile.

-_-_. (1902). Memoria Anual del Ministerio de Relaciones Exteriores de Chile. Santiago, Chile.

-_-_. (1909). Memoria Anual del Ministerio de Relaciones Exteriores de Chile. Santiago, Chile.

-———. (1911). Memoria Anual del Ministerio de Relaciones Exteriores de Chile. Santiago, Chile.

- - - . (junio 2014). Chile y la aspiración marítima boliviana: miito y realidad. Recuperado de http://www.minrel.gob.cl/minrel/site/artic/20140624/asocfile/20140624134912/ chile_y_la_aspiraci_n_mar_tima_boliviana_mito_y_realidad.pdf

Montenegro, C. (1943). Nacionalismo y coloniaje. La Paz, Bolivia: Ediciones Autonomía.

Neira, M. (2004). Jeremy Bentham y el liberalismo en Chile durante la primera mitad del siglo XIX. Boletín de la Academia Chilena de la Historia LXX (113), 285-313.

Rodríguez Ostria, G. (2014, 30 de marzo). La Razón. Disponible en http://www.la-razon. com/opinion/columnistas/Montenegro-Pacifico_0_2024197693.html

Ross, C. (2012). Los desafíos de la política exterior chilena. En M. Artaza y C. Ross (eds.), La política exterior de Chile, 1990-2009: Del aislamiento a la integración global (pp. 853880). Santiago, Chile: RIL Editores/USACH. 
Sánchez, D. (1919). Bolivia, su estructura y sus derechos en el Pacífico. Arnó hermanos, Bolivia.

Sater, W. F. (1973). The heroic image in Chile: Arturo Prat, Secular Saint. Berkeley, Estados Unidos: University of California Press.

Subercaseaux, B. (1980). Liberalismo positivista y naturalismo en Chile (1865-1875). Revista de Crítica Literaria Latinoamericana 6 (11), 7-27.

Tannen, D., Hamilton, H. E. y Schiffrin, D. (eds.). (2015). The handbook of discourse analysis. Malden, MA: Wiley Blackwell.

Naciones Unidas. (1994). Convemar. Recuperado de Convención de las Naciones Unidas sobre el Derecho del Mar. Disponible en http://www.un.org/Depts/los/convention_ agreements/texts/unclos/convemar_es.pdf

Van Dijk, T. (1999). El análisis crítico del discurso. Anthropos 186, 23-36.

(2012). Discurse and knowledge. En Gee, J. P. y Handford, M. The routledge handbook of discourse analysis (pp. 587-603). Nueva York, Estados Unidos: Routledge,

- - —. (2015). Critical Discouse Analisys. En Tannen, D., Hamilton, H. E. y Schiffrin, D. (eds.). The Handbook of Discourse Analysis (pp.466-484). Malden, MA: Wiley Blackwell.

Villalobos, S. (1987). Origen y ascenso de la burguesía en Chile. Santiago, Chile: Universitaria.

Wilson, John (2015). Political discouse. Historical Discourse Analisys. Tannen, D., Hamilton, H. E. y Schiffrin, D. (eds.). The Handbook of Discourse Analysis (pp. 775-794). Malden, MA: Wiley Blackwell.

Wodak, R. y Chilton, P. (2005). A New Agenda in (Critical) Discourse Analysis :Theory, Methodology and Interdisciplinarity. Amsterdam: John Benjamins Publishing Co.

Wodak, R. (2012). Politics as usual: Investigating political discourse in action. En Gee, J. P. y Handford, M. The routledge handbook of discourse analysis (pp. 525-540). Nueva York, Estados Unidos: Routledge.

Zea, L. (1976). El pensamiento latinoamericano. Barcelona, España: Ariel. . (1980). Pensamiento positivista latinoamericano. Caracas, Venezuela: Biblioteca Ayacucho.

210 Si Somos Americanos. Revista de Estudios Transfronterizos 